\title{
Decadal variation of different durations of continuous Meiyu precipitation and the possible cause
}

\author{
HUANG DanQing ${ }^{*}$, ZHU Jian \& KUANG XueYuan \\ School of Atmospheric Sciences, Nanjing University, Nanjing 210093, China
}

Received July 23, 2010; accepted October 11, 2010

\begin{abstract}
The features of the decadal evolution of different durations of continuous Meiyu precipitation and their possible cause from the viewpoint of the low-level intraseasonal oscillation (ISO) are examined in this study. It is found that the total frequency of Meiyu precipitation events of certain duration gradually decreases as the duration of the events increases, and the main center of the events moves from the northern Yangtze-Huaihe River Valley (YHRV) to the southern YHRV. The linear trends of different durations of continuous Meiyu precipitation indicate that longer-duration precipitation has become significantly less frequent since 2000, while 2-day and 3-4-day continuous precipitation processes have become more frequent. At the same time, a close relationship between the variation in the low-level ISO and the decadal evolution of frequency of longer-duration Meiyu precipitation is detected. Clearly, since 2000, the low-level ISO has significantly decreased, and a single peak of longer-duration events has been replaced by several peaks of shorter-duration events, which has resulted in a significant decrease in the frequency of longer-duration precipitation. Meanwhile, low-level baroclinicity increased (decreased) during each period, which is in accordance with the increasing (decreasing) frequency of longer-duration precipitation. It is confirmed that longer-duration precipitation has significantly decreased in recent years.
\end{abstract}

Meiyu, different durations of continuous precipitation, intraseasonal oscillation, low-level baroclinicity

Citation: Huang D Q, Zhu J, Kuang X Y, et al. Decadal variation of different durations of continuous Meiyu precipitation and the possible cause. Chinese Sci Bull, 2011, 56: 424-431, doi: 10.1007/s11434-010-4241-x

Meiyu is a unique rainy season over East Asia during the northward progress of the East Asian summer monsoon from late spring to middle summer. In addition, it is an important weather and climate phenomenon affecting eastern China during summer. The intensity of Meiyu precipitation, the length of the Meiyu season and other parameters not only reflect the seasonal evolution of atmospheric circulation over Asia and the adjustment of the circulation process, but also directly relate to the persistence of drought and flood over the Yangtze-Huaihe River Valley (YHRV, $\left.28^{\circ}-34^{\circ} \mathrm{N}, 110^{\circ}-122^{\circ} \mathrm{E}\right)$. Consequently, the evolution of Meiyu climate change is an important issue in understanding the regional climate and climate change throughout the YHRV.

*Corresponding author (email: huangdq@nju.edu.cn)
Chinese meteorologists have carried out many studies on the decadal variation of Meiyu systems. Wei et al. [1] and Chen et al. [2] examined the abrupt shift of Meiyu parameters during 1885-2005. Their results indicated an abrupt shift of the length and onset of Meiyu. Furthermore, oscillation of the Meiyu belt was investigated on interannual and decadal scales. On the basis of daily precipitation data recorded at 180 stations throughout eastern China, Xu et al. [3] found an abrupt shift of the boundary and area index of the Meiyu region during the late 1970s and early 1980s. Wu et al. [4] compared station data from China, Japan and South Korea and found that the rainy mode for southeastern China, the middle and lower reaches of the Yangtze River, and northeastern China abruptly shifted around 1978-1979. $\mathrm{Xu}$ [5] reported a strong decadal change in the Meiyu period for the mid-lower Yangtze basin in the late 1970s for a 
study period of 1885-2000: a weak Meiyu stage in 1959 -1978 abruptly transformed into a strong stage in 1979-1999, and a new stage of weaker Meiyu started in 2000. In recent years, many scholars have mentioned a new evolution of Meiyu: since 2000, Meiyu precipitation has increasingly concentrated on the Huaihe River Basin north to $33^{\circ} \mathrm{N}[6-8]$.

The previous studies paid more attention to the decadal shifts of the Meiyu parameters, Meiyu precipitation and rainfall belt. However, continuous precipitation is one of the most important features during the Meiyu season and is closely related to persistent floods over the YHRV. Therefore, it is of interest to understand the evolutions of different durations of continuous Meiyu precipitation and establish whether the frequency of the longer-duration precipitation has significantly decreased since 2000. Furthermore, the causes of any decrease in frequency would need to be investigated. To date, less attention has been paid to the features of different durations of continuous precipitation, but they are worthy of analysis. Here we examine the evolution of various features of continuous precipitation, especially longer-duration precipitation, which will help clarify the "atypical changes" of Meiyu.

\section{Data and methods}

The daily precipitation data of 738 stations in China were provided by the National Meteorological Information Center. The period is from January 1960 to December 2007. In this study, the stations over the YHRV are selected. Because most droughts and floods during June and July have been caused by Meiyu precipitation anomalies, we document the Meiyu period as June and July over the YHRV in this study.

In the analysis of the characteristics of different kinds of continuous Meiyu precipitation, continuous precipitation was firstly divided into periods of 2-day, 3-day, 4-day, 5-day, and 6-day continuous rainfall and so on, giving a total of 10 categories. Comparing the characteristics of different durations of continuous Meiyu precipitation, we found that the features of some durations of continuous rainfall are similar (figure omitted). Finally, 2-day (C2), 3-4-day (C34), and more than 5-day continuous rainfall (C5) were selected in this study. Various durations of continuous precipitation were calculated independently; for example, C34 does not include C2. The frequency of certain duration of continuous precipitation is the number of such rainfall events in a year.

The atmospheric data for analysis are taken from NCEP/NCAR (National Centers for Environmental Prediction/National Center for Atmospheric Research) reanalysis daily datasets, with a spatial resolution of $2.5^{\circ} \times 2.5^{\circ}$ in longitude and latitude and a period from January 1948 to January 2010. We considered variables of zonal wind, merid- ional wind and temperature at 850 and $700 \mathrm{hPa}$. Because there are uncertainties in NCEP/NCAR reanalysis datasets at low levels around 1979 [9-12], the atmospheric dataset from the European Centre for Medium-range Weather Forecasts (ECMWF) reanalysis daily datasets named ERA-40, with a spatial resolution of $2.5^{\circ} \times 2.5^{\circ}$ in longitude and latitude and a period from September 1957 to August 2002, were used for comparison with NCEP/NCAR data.

According to the bandpass-filter technique based on the work of Hamming [13], the intraseasonal oscillation (ISO) with a 30-60-day period was extracted from the daily datasets of NCEP/NCAR and ERA-40. The ISO daily data during the Meiyu period were used to represent the ISO signal during the Meiyu period in each year. Meanwhile, the baroclinicity was represented by the maximum Eady growth rate (MEGR) [14,15], calculated as $\sigma_{B I}=0.31 g N^{-1} \mathrm{~T}^{-1}|\partial \bar{T} / \partial y|$, where $T$ is the zonal mean temperature and $N$ is the Brunt-Vaisala frequency calculated using $T$. The value reflects the baroclinicity.

\section{Results}

\subsection{Frequency}

Figure 1 shows the frequency distribution of different durations of continuous Meiyu precipitation during 1960-2007. As shown in Figure 1(a), the total frequency of $\mathrm{C} 2$ is greater than 100, being less in the southern YHRV and more in the northern YHRV. Figure 1(b) and (c) indicates large centers of C34 and C5 located over the middle of the YHRV, Yangtze River Delta and lower reaches of the southern YHRV. Overall, it is apparent that the total frequency of a particular duration of continuous Meiyu precipitation decreased gradually with increasing duration, and the largest center moves from the north to the south of the YHRV.

\subsection{Standard deviation}

Many important studies have illustrated that the location of the Meiyu belt and Meiyu precipitation experienced a notable regime shift around 1979/1980 [16-21]. Meanwhile, recent studies revealed a new evolution of Meiyu precipitation since 2000 [5-8]. To compare decadal differences, especially the features of different durations of continuous precipitation since 2000 , the total study period of 1960 2007 was divided into three sub-periods as 1960-1979, 1980-1999 and 2000-2007.

From the analysis of total frequency, the features of three different durations of continuous precipitation are revealed. However, it needs to be determined if there are annual fluctuation anomalies in different periods. The extent of change in each year can be found from the standard deviation.

Over time, the large centers of the standard deviation of C2 (Figure 2(a), (d), (g)) are located over the northeastern, northwestern and southeastern YHRV. In these areas, the 

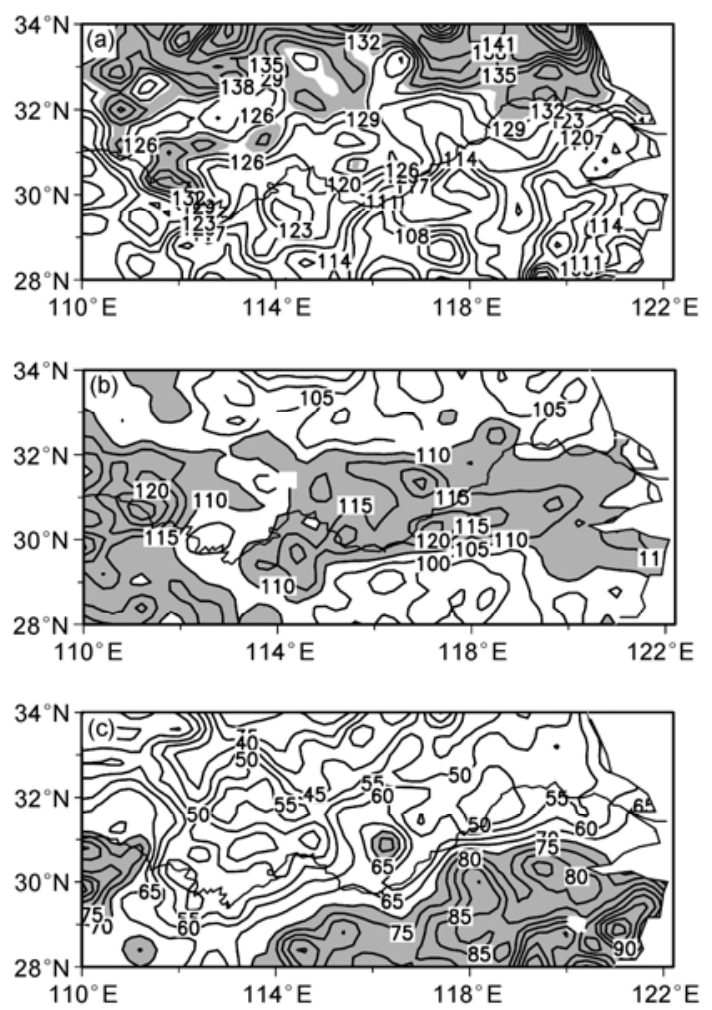

Figure 1 Total distribution of different durations of continuous precipitation during 1960-2007 (unit: times) (values above 130, 110, and 70 are shaded in (a), (b) and (c), respectively). 2-day continuous precipitation occurred more frequently in some years and less frequently in other years. In the spatial distribution of the standard deviation of C34 (Figure 2(b), (e), (h)) during the three sub-periods, the large centers are all found in the southern YHRV, especially during the period of 1960-1979, while the standard deviation of C34 is less for 2000-2007. Figure 2(c), (f), (i) present the patterns of the standard deviation of C5 during 1960-1979, 1980-1999, and 2000-2007, respectively. They suggest that during 1980-1999, the maximum center was located in the northeastern YHRV, while during 1960-1979 and 2000-2007, the large centers were in the southeastern YHRV, especially after 2000.

\subsection{Linear trend}

Figure 3 shows the spatial distribution of significant linear trends of different durations of continuous Meiyu precipitation during the period of 1960-1979. For C2 (Figure 3(a)), there is a significant increasing trend concentrated along the Yangtze River Valley. The significant trends of C34 (Figure $3(b))$ are located over the eastern YHRV at $118^{\circ} \mathrm{E}$. There is a boundary almost running along $30^{\circ} \mathrm{N}$, with significant increasing trends to the south and decreasing trends to the north. The north-south dipole was found for the trend distribution of $\mathrm{C} 5$, with significant increasing trends in the northern YHRV and decreasing trends in the southern YHRV.

Similar to Figure 3, significant linear trends during the
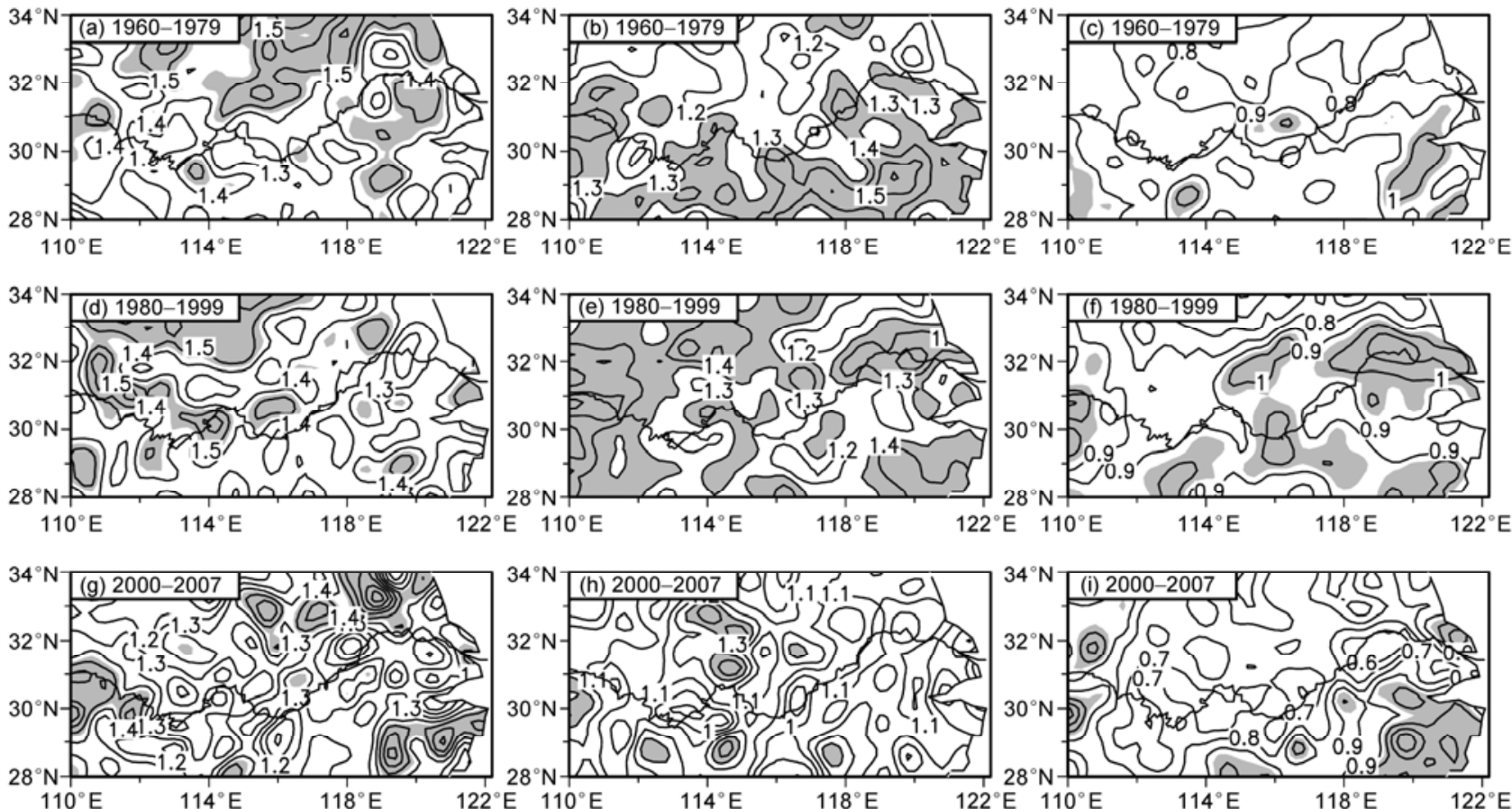

Figure 2 Standard deviation distributions of different durations of continuous precipitation during each period (values above 1.45, 1.3, and 0.95 are shaded in (a), (d), (g), (b), (e), (h) and (c), (f), (i), respectively). 

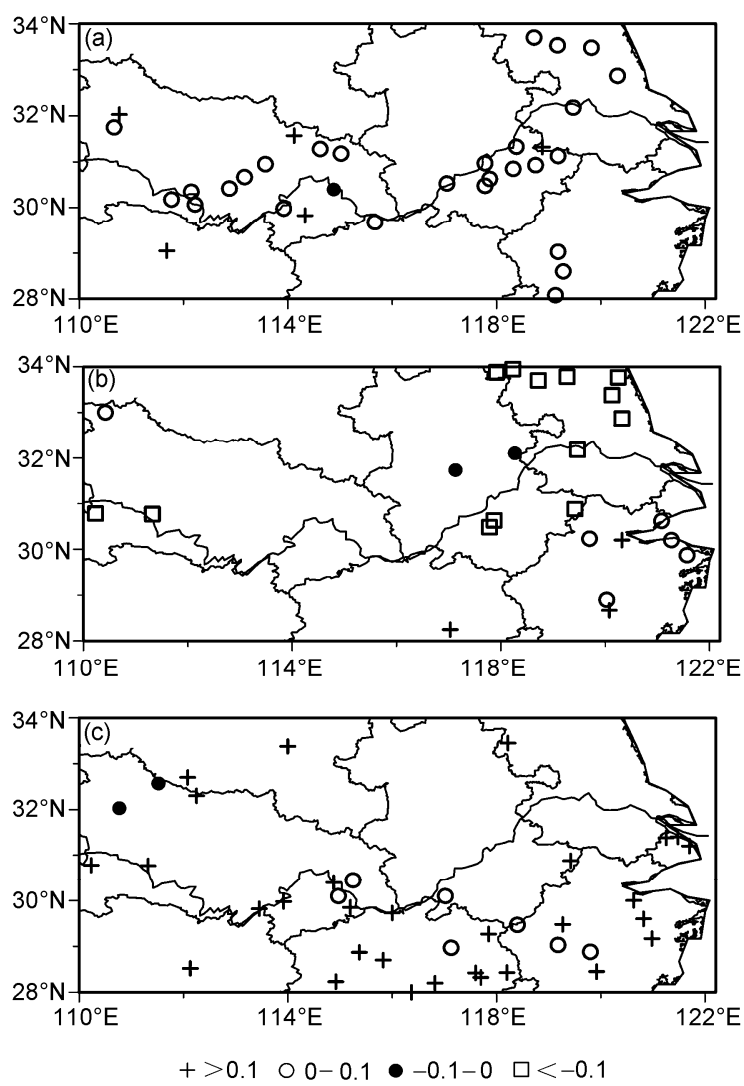

Figure 3 The linear trend distribution of different durations of continuous precipitation during 1960-1979 (unit: times/a) (values with magnitudes larger than the $95 \%$ confidence level are indicated in the figures).

period of 1980-1999 are presented in Figure 4. Clearly, there are significant differences in the trends of different durations of continuous precipitation. Significant decreasing trends (Figure 4(a)) are found for C2, especially in the Yangtze River Delta. There are significant decreasing trends in the distribution of C34 (Figure 4(b)), except in northern Hunan province. There is an apparent " +-+ " pattern from south to north over the YHRV. The distribution of C5 has a similar pattern in 1960-1979; there is a north-south dipole pattern with increasing trends in the southern YHRV and deceasing trends in the northern YHRV.

For the period of 2000-2007 (Figure 5(a)), significant increasing trends of $\mathrm{C} 2$ are found in a southwest-northeast line, and the frequency of C2 peaks over the Yangtze River Delta. Significant increasing trends of C34 (Figure 5(b)) are found to the east of $116^{\circ} \mathrm{E}$, while the trends over the northern YHRV are the opposite. Figure 5(c) indicates that the significant increasing trends of C5 move from the southern YHRV to the northern YHRV, which corresponds well with what is observed for 1980-1999. The shift is also in accordance with the results of the latest study by $\mathrm{Si}$ et al. [7], which detected a northward shift of the Meiyu belt. Overall, it is seen that longer-duration precipitation decreased significantly during 2000-2007.
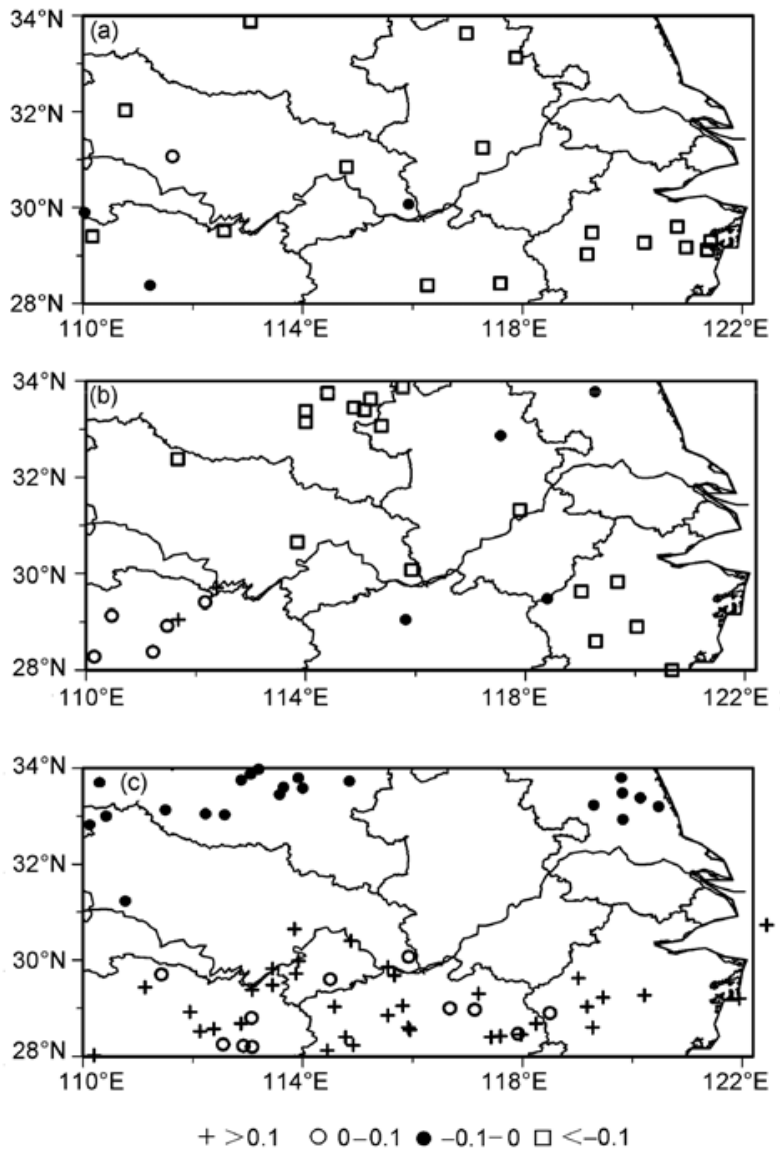

Figure 4 As for Figure 3, but for 1980-1999.

Overall, the present study finds that in recent years (20002007), longer-duration precipitation decreased significantly over the southern Yangtze River, and there was an associated increase in the frequency of $\mathrm{C} 2$ and $\mathrm{C} 34$ as a result of unexpected precipitation events. However, this is inconsistent with typical features of the Meiyu period (e.g. longer rain events with less sunlight and more humidity [22]), which also be evidence for atypical change of the Meiyu season in recent studies [5-8].

\section{Possible relationship with low-level ISO}

The above significant increasing trends of C5 were found over the YHRV for the period of 1980-1999, while after 2000, longer-duration precipitation significantly decreased, especially over the southern YHRV. We now attempt to explain the decadal variation in continuous precipitation, especially the abrupt shift in longer-duration precipitation around 2000. Previous studies have suggested that there is close relation between continuous heavy precipitation and ISO signals, especially in the case of low-level ISO winds [23-30]. In this study, we attempt to discuss the possible relationship between the low-level ISO winds and decadal 

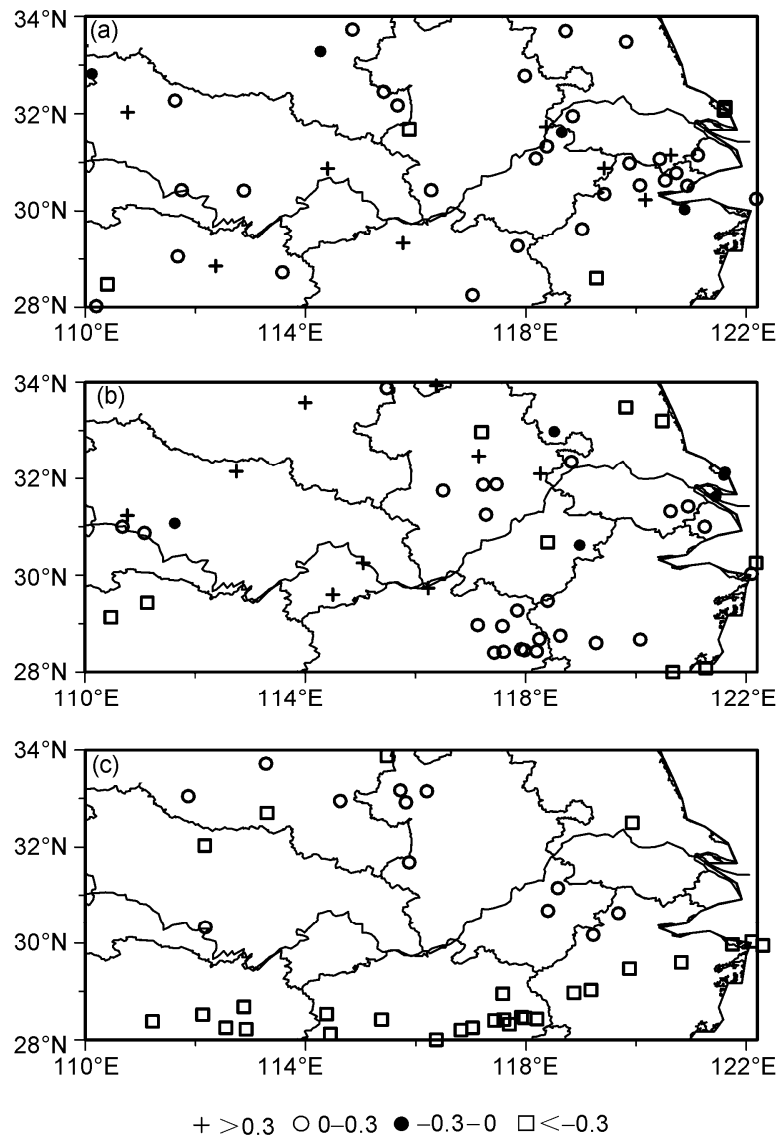

Figure 5 As for Figure 3, but for 2000-2007.

variation in longer-duration precipitation over the YHRV.

First, with the backgrounds of different periods, the different durations of continuous precipitation change. Because baroclinicity reflects uneven heating and the strength of atmospheric instability, it directly affects precipitation processes. Figure 6 gives the differences of low-level MEGR during each period. Comparing the average MEGR between 1980-1990 and 1960-1979 (Figure 6(a)), an apparent east-west "+ -" dipole is found at middle and high latitudes. The baroclinicity is significantly enhanced in the YHRV, which increases precipitation during the period of 1980-1999. However, comparing the average MEGR be-
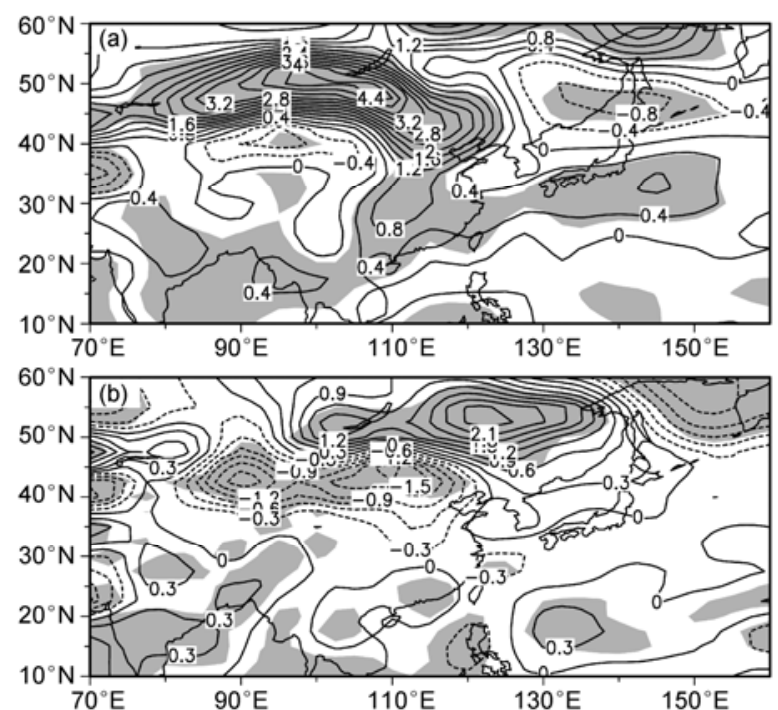

Figure 6 The difference in MEGR at $850 \mathrm{hPa}$ between the average for 1980-1999 and the average for 1960-1979 (a) and the average for 2000-2007 and the average for 1980-1999 (b) (unit: $10^{6} \mathrm{~d}^{-1}$ ). Values with magnitude larger than $90 \%$ confidence level are shaded.

tween 2000-2007 and 1980-1999 (Figure 6(b)), a southnorth " -+ " dipole is found at middle and high latitudes. The area of the negative anomaly extends to the YHRV, which corresponds well with the decrease in longer-duration precipitation over the YHRV.

As mentioned above, the background biases in different periods have not been conducive to maintaining the longerduration precipitation over the YHRV in recent years. We ask whether this can be verified from the daily low-level ISO winds during different periods. Figure 7 presents the time series of daily low-level ISO winds during the Meiyu season in different periods. It is noted that in the NCEP/ NCAR reanalysis data (Figure 7(a)), a longer-duration peak of the low-level ISO winds is found approximately from late June to mid-July during 1960-1979, which is in accordance with the longer-duration precipitation processes. In 1980-1999, the distribution is similar to that in 1960-1979, while the peak time is slightly delayed. However, in recent years, the structure with a longer-duration single peak has

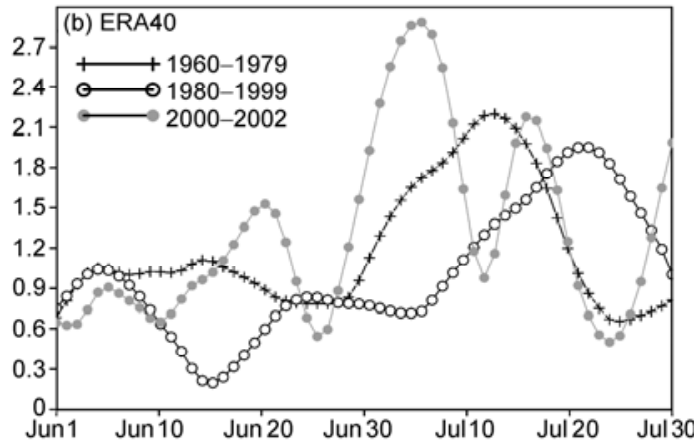

Figure 7 The daily evolution of low-level ISO wind speed during the Meiyu season in different periods (unit: $\mathrm{m} / \mathrm{s}$ ). 
been replaced by a distribution with several shorter-duration peaks, and the occurrence of continuous precipitation processes is earlier. This is in accordance with the latest studies [5] and verifies that there have been significantly less processes of longer duration in recent years than in the first two periods. Similar conclusions are found in the analysis of the ERA40 reanalysis data (Figure 7(b)).

To further examine the decadal evolution, Figure 8 gives the latitude and longitude average time evolution of the frequency anomalies of C5 during 1960-2007. Clearly, the frequency of C5 significantly decreases during 1960-1965, and the rainy belt is from $28^{\circ} \mathrm{N}$ to $33^{\circ} \mathrm{N}$. Otherwise, during the period of 1990-2007, C5 changed acutely. In 19902000 , the frequency of longer-duration precipitation significantly increased south of $32^{\circ} \mathrm{N}$ over the YHRV, while it significantly decreased in the same region after 2000. Meanwhile, as well as the increase/decrease in the frequency of $\mathrm{C} 5$ in different periods, there is also a rainy belt in a south-north direction. In addition, similar results are found for the distribution of the longitude-average evolution

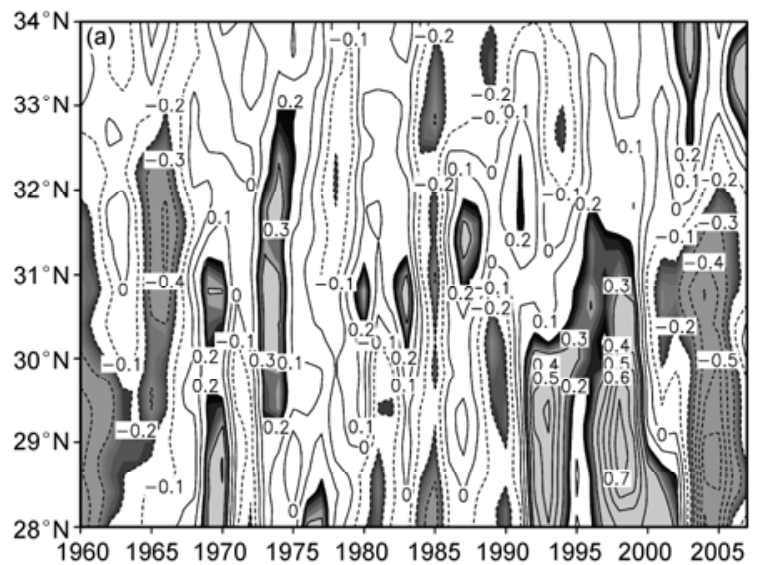

(Figure 8(b)), and over time, the frequency of longer-duration precipitation extends from east to west.

Similarly, the latitude-time cross section of the longitude average of low-level ISO winds is given in Figure 9. In the case of the NCEP/NCAR reanalysis data (Figure 9(a)), the positive center of the ISO is in accordance with that of the frequency of C5, especially during the period of 1990-2007. In 1992-2000, significant positive anomalies are found in the ISO and the frequency of longer-duration precipitation, especially along $20^{\circ} \mathrm{N}$ and $35^{\circ} \mathrm{N}$. However, in recent years, the low-level ISO wind anomalies have changed to a negative phase, which is in agreement with C5 anomalies. The ERA40 reanalysis data (Figure 9(b)) can well capture the features of positive anomalies during the 1990s, which extend to $35^{\circ} \mathrm{N}$, while negative anomaly signals are found between $25^{\circ} \mathrm{N}$ and $40^{\circ} \mathrm{N}$ after 2000 . This is in accordance with the evolution of longer-duration precipitation. The results for the latitude-average time cross section are similar to those for the longitude-average fields (figure omitted), which indicates a close relation between ISO anomalies and

Figure 8 Latitude-time cross section averaged for $110^{\circ}-122^{\circ} \mathrm{E}$ (a) and the longitude-time cross section averaged for $28^{\circ}-34^{\circ} \mathrm{N}$ (b) for the $\mathrm{C} 5$ anomalies during the Meiyu season in 1960-2007 (unit: times).
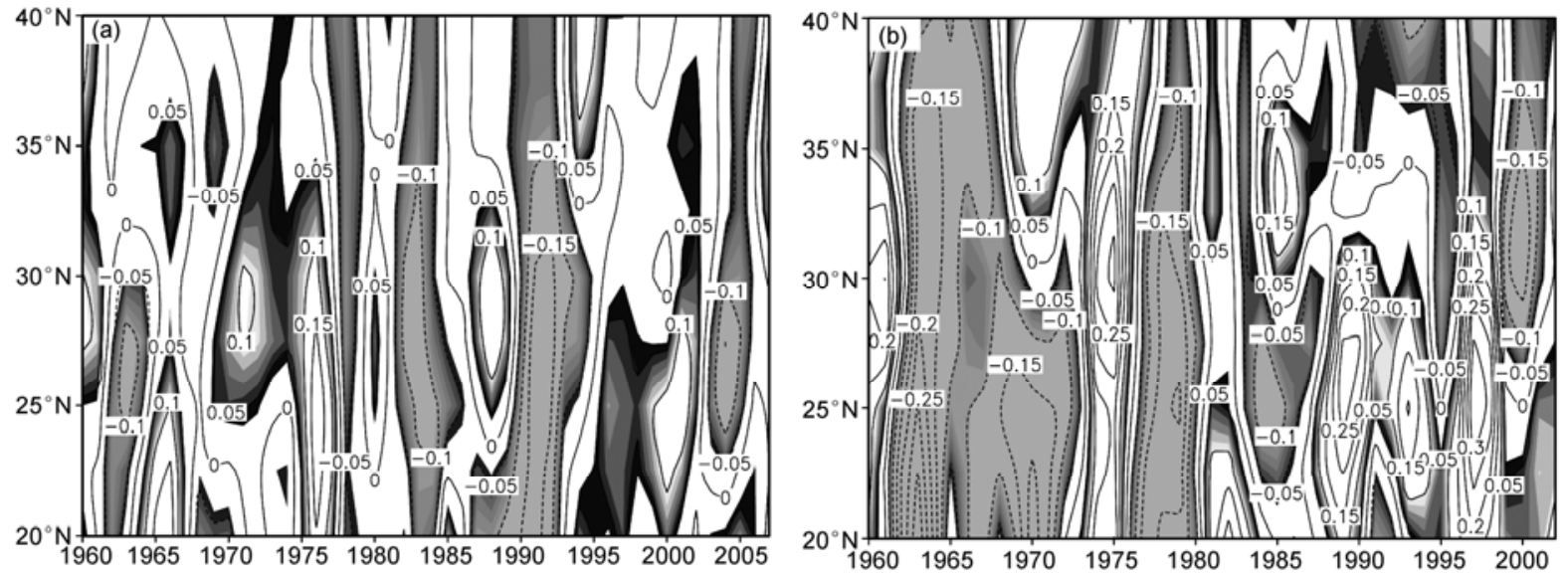

Figure 9 Latitude-time cross section of low-level ISO wind speed anomalies averaged for $110^{\circ}-122^{\circ} \mathrm{E}$ during the Meiyu season in $1960-2007$ (unit: m/s). (a) NCEP/NCAR: 1960-2007; (b) ERA40: 1960-2002.

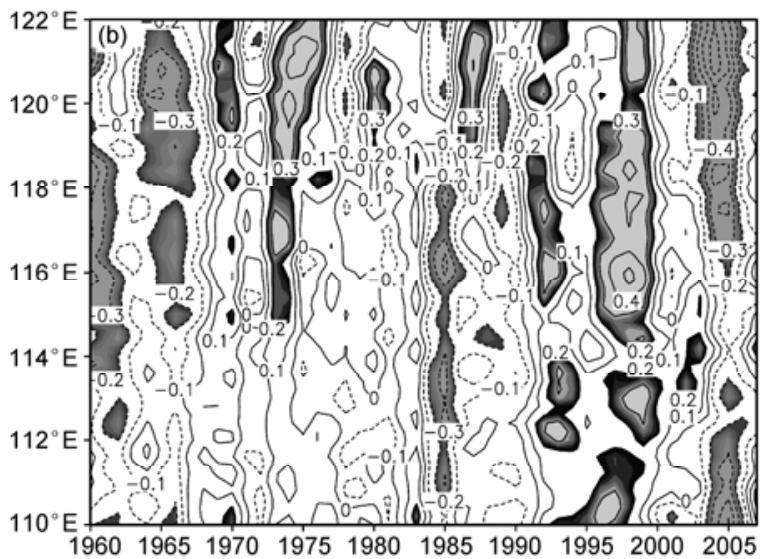


the evolution of longer-duration precipitation.

\section{Conclusions}

This paper analyzed the features of varying durations of continuous Meiyu precipitation. Since 2000, a significant decreasing trend of longer-duration precipitation over the YHRV during the Meiyu season was revealed from daily observation data. From the viewpoint of low-level ISO winds, a possible mechanism for the decadal evolution of the frequency of C5 was discussed. The following conclusions were obtained.

(1) In the case of the climatological mean, during the Meiyu season over the YHRV, the frequency of C2 is largest, while C5 is the least. Furthermore, with an increase in the number of days of continuous precipitation, total frequency has gradually decreased, and the rainy belt has moved from the northern to the southern YHRV.

(2) In the standard deviation fields, the annual differences in the frequencies of different durations of continuous precipitation were the largest during 1980-1999, especially for the C34 distribution. However, in recent years, the interannual difference in each duration of continuous Meiyu precipitation has decreased, and the center of the maximum is over the southeastern YHRV.

(3) The linear trends for different durations of continuous precipitation significantly increased for the $\mathrm{C} 2$ distribution over the southern Yangtze River and decreased over the northern Yangtze River during the periods 1960-1979 and 1980-1999. In the C5 distribution, there were significant increasing trends over the southern YHRV, especially during 1980-1999. In recent years, the frequency of C2 has significantly increased, especially for the Yangtze River basin. However, the opposite distribution is found for the frequency of $\mathrm{C} 5$, especially in the area of $28^{\circ}-30^{\circ} \mathrm{N}$.

(4) There has been a close relationship between the decadal evolution of the frequency of C5 and ISO anomalies, especially during 1990-2007. Since 2000, a longer-duration single-peak structure has been replaced by a distribution with several shorter-duration peaks, and the occurrence time of the continuous precipitation processes has become earlier. Meanwhile, low-level baroclinicity has increased (decreased) during each period, which is in accordance with the increasing (decreasing) frequency of longer-duration precipitation. It was confirmed that longer-duration precipitation has significantly decreased in recent years.

It should be pointed out that the present study is a preliminary diagnostic analysis. A related numerical simulation and dynamical analysis needs to be carried out as future work.

We thank the editor and two anonymous reviewers for their valuable comments and suggestions. The NCEP/NCAR reanalysis data were provided by the National Centers for Environmental Prediction and National Center for Atmospheric Research. The ERA-40 reanalysis data were provided by the European Centre for Medium-range Weather Forecasts. This work was supported by the National Department Public Benefic Research Foundation (GYHY200906015), the National Key Technology R\&D Program (2009BAC51B03), and the National Natural Science Foundation of China (40901016 and 40805041).

1 Wei F Y, Zhang J J. Climatic variation of Meiyu in the middle-lower reaches of Changjiang River during 1885-2000 (in Chinese). Quart J Appl Meteor, 2004, 15: 313-320

2 Chen Y M, Qian Y F. Climatic characteristics of 116-year Meiyu rainfall in the mid-lower reaches of the Changjiang River (in Chinese). J Nanjing Institute Meteor, 2004, 27: 65-72

$3 \mathrm{Xu} \mathrm{W} \mathrm{G,} \mathrm{Jiang} \mathrm{J.} \mathrm{Characteristics} \mathrm{of} \mathrm{the} \mathrm{rainbelt} \mathrm{of} \mathrm{Meiyu} \mathrm{between}$ interannual and interdecadal climate variations (in Chinese). J Nanjing Univ, 2004, 40: 292-303

4 Wu R G, Wang B. A contrast of the east Asian summer monsoon and ENSO relationship between 1962-1977 and 1978-1993. J Clim, 2002, 15: 3266-3279

$5 \mathrm{Xu}$ Q. Recent strong decadal change of Meiyu in 121 years (in Chinese). Adv Water Sci, 2007, 18: 327-335

6 Liang P, He J H. Review for climate change of Meiyu over the Yangtze-Huaihe basins (in Chinese). Plateau Meteor, 2008, 27: 1-15

7 Si D, Ding Y H, Liu Y J. Decadal northward shift of the Meiyu belt and the possible cause. Chinese Sci Bull, 2009, 54: 4742-4748

8 Liang P, Ding Y H. Climate change of Meiyu in Shanghai in past a century (in Chinese). Plateau Meteor, 2008, 27: 76-83

9 Huang G. The assessment and difference of the interdecadal variations of climate change in northern part of China with the NCEP/NCAR and ERA-40 reanalysis data (in Chinese). Clim Environ Res, 2006, 11: 310-320

10 Wu R, Kinter J L, Kirtman B P. Discrepancy of Interdecadal Changes in the Asian Region among the NCEP/NCAR Reanalysis, Objective Analyses, and Observations. J Clim, 2005, 18: 3048-3067

11 Inoue T, Matsumoto J. A comparison of summer sea level pressure over east Eurasia between NCEP/NCAR reanalysis and ERA-40 for the period of 1960-99. J Meteor Soc Jpn, 2004, 82: 951-958

12 Yang S, Lau K M, Kim K M. Variations of the east Asian jet stream and Asian-Pacific-American winter climate anomalies. J Clim, 2002, 15: $306-325$

13 Hamming R W. Digital Filters. 3rd ed. Hertfordshire: Prentice Hall International (UK) Ltd, 1989. 284-302

14 Yin J H. A consistent poleward shift of the storm tracks in simulations of $21^{\text {st }}$ century climate. Geophys Res Lett, 2005, 32: L18701, doi:10.1029/2005GL023684

15 Lindzen R S, Farrell B F. A simple approximate results for maximum growth rate of baroclinic instabilities. J Atmos Sci, 1980, 60: 1490 $-1503$

16 Murakami M. Large-scale aspects of deep convective activity over the GATE area. Mon Weather Rev, 1979, 107: 994-1013

$17 \mathrm{Xu}$ Q. Abrupt change of the mid-summer climate in central east China by the influence of atmospheric pollution. Atmos Environ, 2001, 35: 5029-5040

18 Gong D Y, Ho C H. Shift in the summer rainfall over the Yangtze River valley in the late 1970s. Geophys Res Lett, 2002, 29: 1436, doi: 10.1029/2001GL014523

19 Weng H, Lau K M, Xue Y. Multi-scale summer rainfall variability over China and its long-term link to global sea surface temperature variability. J Meteor Soc Jpn, 1999, 77: 845-857

20 Ding Y, Wang Z, Sun Y. Inter-decadal variation of the summer precipitation in East China and its association with decreasing Asian summer monsoon. Part I: Observed evidences. Int J Climatol, 2007, 28: 1139-1161

21 Zhu X Y, He J H, Wu Z W. Meridional seasaw-like distribution of the Meiyu rainfall over the Changjiang-Huaihe river valley and characteristics in the anomalous climate years. Chinese Sci Bull, 2007, 52: 2420-2428

22 Liu D N, He J H, Yao Y H. Review and outlook of Meiyu (in Chi- 
nese). Meteor Disaster Reduction Res, 2009, 32: 1-9

23 Wen Z P, Dong L Y, Wu L J, et al. The characteristics of 30-60 day oscillation and its relation to the durative rainstorm in Guangdong (in Chinese). Acta Sci Natur Univ Sunya, 2007, 46: 98-103

24 Yang H, Yang C Y. The relation between atmospheric intraseasonal oscillation and summer severe flood and drought in the Changjiang-Huaihe river basin. Adv Atmos Sci, 2003, 20: 540-553

25 Han R Q, Li W J, Dong M. The impact of 30-60 day oscillations over the subtropical Pacific on the east Asian summer rainfall (in Chinese). Acta Meteor Sin, 2006, 64: 149-163

26 Sun D, Ju J H, Lu G M. The influence of the intraseasonal oscillation of the east Asian monsoon on the precipitation in east China in 2003 (in Chinese). J Tropic Meteor, 2008, 24: 641-648
$27 \mathrm{Ju} \mathrm{J} \mathrm{H}$, Zhao E X. Impacts of the low frequency oscillation in east Asian summer monsoon on the drought and flooding in the middle and lower valley of the Yangtze River (in Chinese). J Tropic Meteor, 2005, 21: 163-171

28 Mao J Y, Wu G X. Intraseasonal variability in the Yangtze-Huaihe River rainfall and subtropical high during the 1991 Meiyu period (in Chinese). Acta Meteor Sin, 2005, 63: 762-770

29 Qi Y J, Zhang R H, Li T, et al. Impacts of intraseasonal oscillation on the onset and interannual variation of the Indian summer monsoon. Chinese Sci Bull, 2009, 54: 880-884

30 Ren H L, Zhang P Q, Chou J F, et al. Large-scale low-frequency rainfall regimes and their transition modes in summertime over China. Chinese Sci Bull, 2006, 51: 1355-1367

Open Access This article is distributed under the terms of the Creative Commons Attribution License which permits any use, distribution, and reproduction in any medium, provided the original author(s) and source are credited. 